\title{
Design of Compact Microstrip Patch Antenna Using NZIM Lens for Increased Gain
}

\author{
A.S. Pradeep and Dr.G.A. Bidkar
}

\begin{abstract}
The paper presents a Microstrip Patch Antenna (MPA) for WLAN application using a superstrate structure that consists of an array of a 7X7 metamaterial unit cells. An improved broadside gain is obtained with the proposed structure. To obtain the proposed metamaterial unit cell, an extra metal strip is added to the conventional mirrored $S$ like structure. The confirmation of the near-zero index behavior is carried out using the unit cell analysis and parameter extraction using periodic boundary condition. It also confirms the significant reduction in the unit cell foot print. The enhancement of gain using the NZIM (Near Zero Index Metamaterial) lens can be confirmed by simulation results. Similarly there is a reduction of half power beam width in both E-plane and H-plane by 200.
\end{abstract}

Keywords--- Metamaterials, Lens Antenna, NZIM.

\section{INTRODUCTION}

$\mathrm{M}$ ETAMATERIALS are artificial structures having negative permeability, permittivity and refractive index [1]. They have been applied to enhance the efficiency of microwave devices particularly antennas [3]. Recently various schemes based on metamaterial resonator have been proposed to get multipolarization, multiband and band-notched ultra wide band antennacharacteristics as well as control of directive emission from antennas [4]-[11]. The Gain of dipole antenna has been increased using metamaterial structures, like array of rings and metallic rods in [12]. It is shown and demonstrated that Near zero index metamaterial have the capability to control the direction of radiation and convert diverging waves into planar waves [13]. To reduce the height and increase the directivity of a low profile antenna an artificial magnetic conductor substrate and NZIM lens is used respectively [14]. Multibeam radiation and high gain can also be obtained using anisotropic lens [15]. The low directivity is often the design limitation of Microstrip patch antenna even though it has the advantages of simple design principle, conformity with monolithic microwave circuits and polarization tenability. Along with these the characteristics of the unidirectional broadside radiation suits it for wireless communication [16]. In this paper the property of beam focusing of a NZIM lens is analyzed for increased gain and reduced HPBW of an MPA. Unit cell of NZIM is proposed and a 7X7 unit cell of single layer is designed as superstrate over an MPA to increase the broadside performance through ANSYSS HFSS simulations.

A.S. Pradeep, Assistant Professor in the Department of ECE, GEC, Hoovinahadagali

Dr.G.A. Bidkar, Professor, Department of E\&C, SDM College of Engineering \& Technology, Dharwad.

DOI:10.9756/BIJRCE.8204
It is shown that the broad side gain increases by $2 \mathrm{~dB}$ and reduces the beam width considerably in both $\mathrm{E}$ and $\mathrm{H}$ planes as compared to the basic Microstrip patch antenna by incorporation of NZIM lens.

\section{Proposed Antenna Design AND Simulation RESULTS}

\section{A. Basic Microstrip Patch Antenna}

A rectangular Microstrip patch antenna with coaxial feed and operating frequency $5.2 \mathrm{GHz}$ is taken as basic patch design as shown in figure 1 . The length $\mathrm{Lp}=16.5 \mathrm{~mm}$ and width $\mathrm{Wp}=12.6 \mathrm{~mm}$ of this patch are optimized to yield resonating frequency of $5.2 \mathrm{GHz}$. The patch is mounted on FR4 dielectric substrate of height $1.57 \mathrm{~mm}$ whose physical dimensions are Ws $=50 \mathrm{~mm}$ and $\mathrm{LS}=60 \mathrm{~mm}$. The basic patch antenna has impedance bandwidth of $4.25 \%(5.08 \mathrm{GHz}$ - $5.3 \mathrm{GHz}$ ) and gain of $4 \mathrm{~dB}$. ANSYS HFSS is used for simulation and results are shown in figure 2 . andfigure 3.

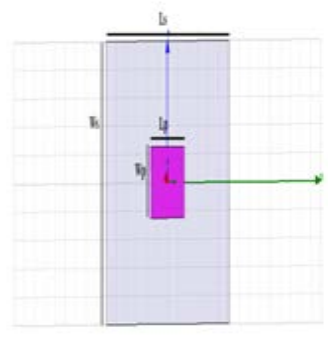

(a)

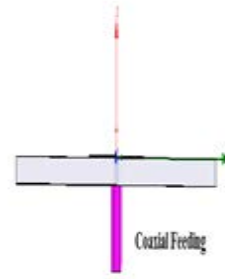

(b)
Figure 1: Schematic Diagram of Coax Fed Microstrip Patch Antenna: (a) Top View (b) Side View

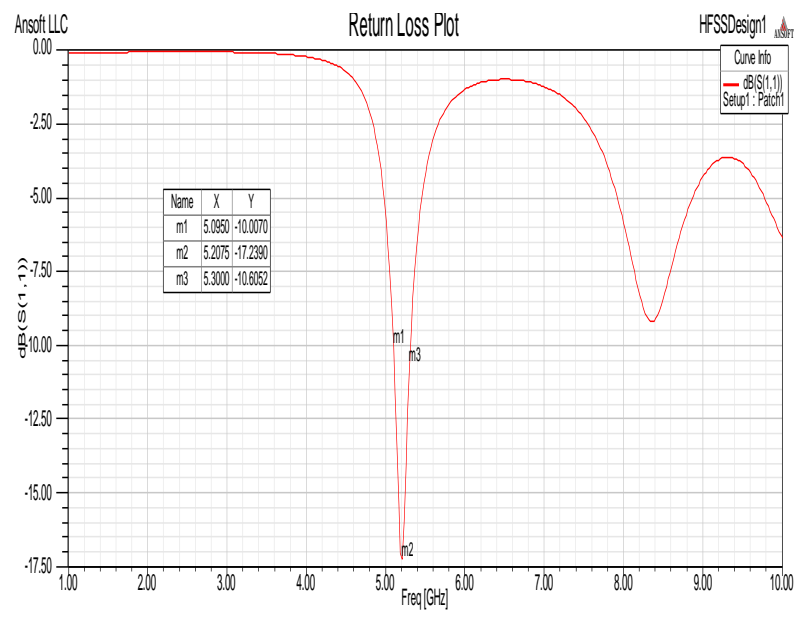

Figure 2: Plot of Return Loss of Basic Patch Antenna Without NZIM Lens 

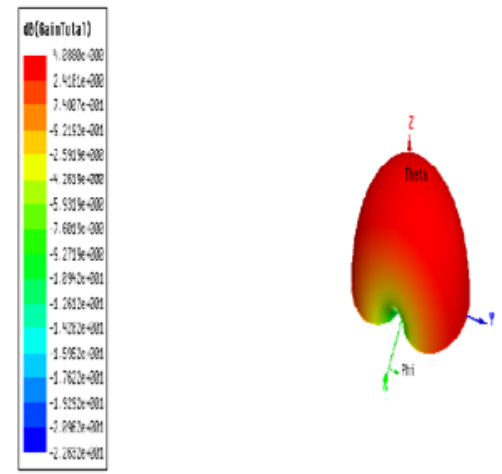

Figure 3: 3D Polar Plot of Gain of Basic Patch Antenna Without NZIM Lens

\section{B. NZIM Unit Cell Design}

A basic building block of NZIM superstrate, the metamaterial unit cell to increase gain of MPA is shown in Figure4. These unit cells are printed on single side of FR4 substrate of thickness $0.8 \mathrm{~mm}$. Figure 4 . shows the design parameters of NZIM unit cell with optimum values to obtain near zero refractive index behavior at $5 \mathrm{GHz}$ frequency range, substrate - FR4, Ax $=$ Ay $=4.5 \mathrm{~mm}, \mathrm{~L} 1=4.2 \mathrm{~mm}, \mathrm{~L} 2=1.725$ $\mathrm{mm}, \mathrm{L} 3=1.2 \mathrm{~mm}, \mathrm{~W} 1=4.3 \mathrm{~mm}, \mathrm{~W} 2=3.5 \mathrm{~mm}, \mathrm{~W}=0.25 \mathrm{~mm}$. The frequency range corresponding to near zero refractive index can be tuned by changing design parameters of NZIM unit cell. Again ANSYS HFSS is used to simulate the unit cell with PEC and PMC boundary condition. The effective medium parameters like permittivity, permeability and refractive index are retrieved from the scattering parameters are explained in [17] and shown in Figure5. andFigure6. By using this NZIM unit cell the significant reduction in the unitcell foot print is achieved as shown in Figure5.

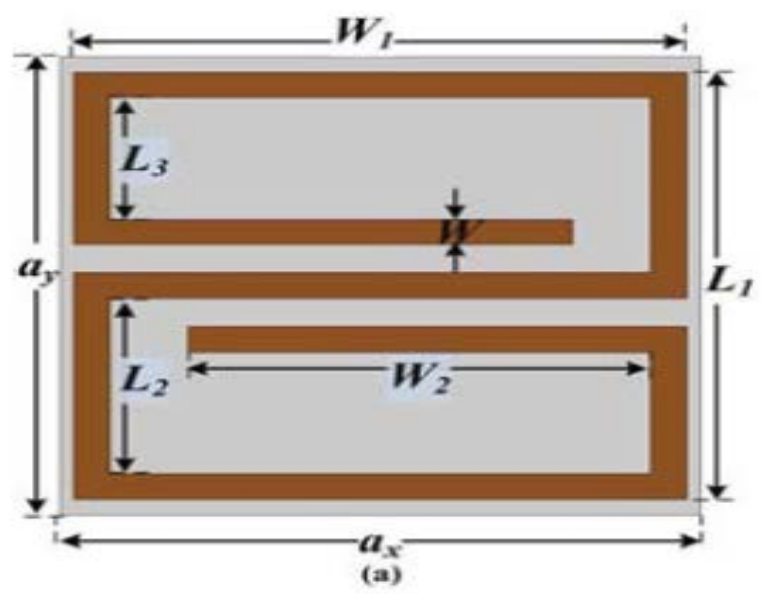

Figure 4: The Schematic Diagram of NZIM Unit Cell

By adding extra metal strips for the mirrored S-like structure, the proposed unit cell is derived. The near zero index frequency region can be matched to the resonant frequency band of antenna through proper control of design parameters of NZIM unit cell.

\section{Patch Antenna with the NZIM Superstrate}

Here, the unit cell proposed earlier is used to design the superstrate or lens which consists of an array of 7X7 unit cells (along $\mathrm{x}$ and $\mathrm{y}$ direction) as shown in fig 8 .

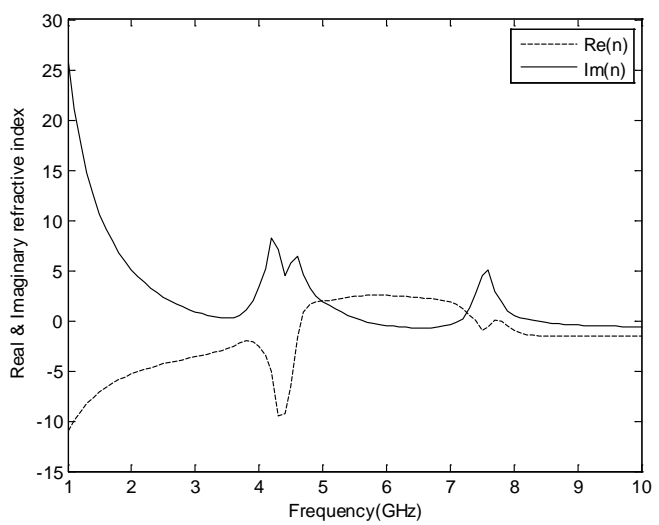

Figure 5: Extracted Real and Imaginary Part of Refractive Index for the Proposed NZIM Unit Cell

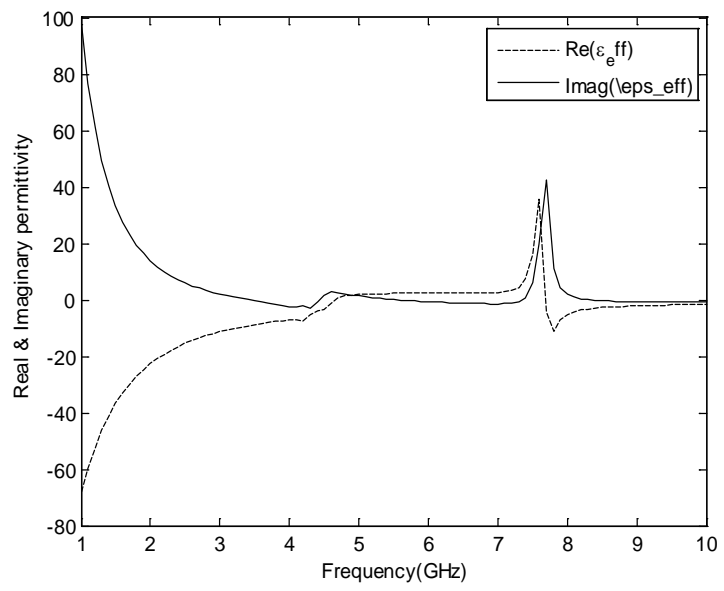

Figure 6: Extracted Real and Imaginary Part of Permittivity for the Proposed NZIM Unit Cell

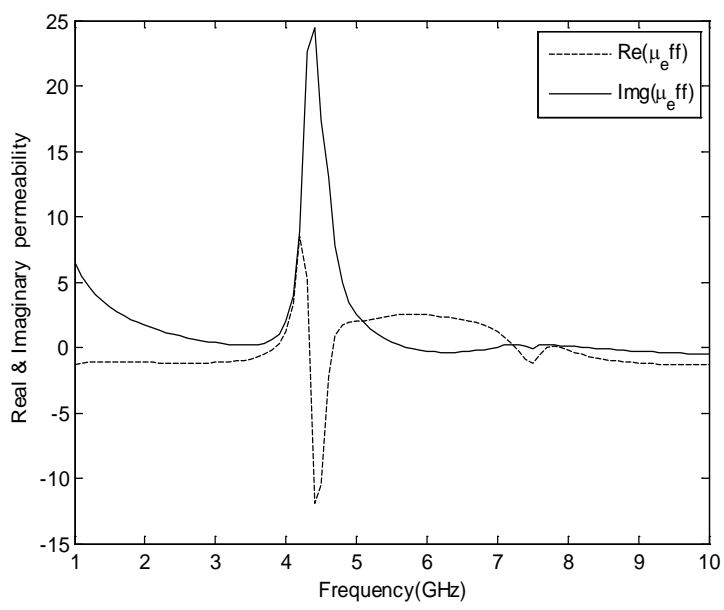

Figure 7: Extracted Real and Imaginary Part of Permeability for the Proposed Nzim Unit Cell 
The performance of the overall antenna system is analyzed. The distance between basic patch antenna and lens is optimized to not have significant coupling between the patch antenna and lens. For this the lens structure is placed at a height of $\mathrm{h}=40 \mathrm{~mm}$ above the patch. This height is approximately $\lambda_{0} / 2$, where $\lambda_{0}$ is the operating wavelength of the MPA. The length and width of the lens is chosen same as the broadside radiation of patch for effective coverage. The plot of return loss S11 and gain of the Microstrip patch antenna with frequency for a single layer of NZIM lens is shown in Figure11. The impedance bandwidth of $4.28 \%$ and gain of $5.46 \mathrm{~dB}$ is observed. The convergence of radiated beam is demonstrated by the linear plot of radiation pattern in $\mathrm{E}$ and $\mathrm{H}$ plane as shown in Figure9 and Figure 10. It is seen that HPBW in E-plane ( $\theta \mathrm{E}$ ) is reduced from 900 to 580 and HPBW in H-plane $(\theta \mathrm{H})$ is reduced from 720 to 510 . Hence the concept of gain enhancement by convergence of beam is verified.

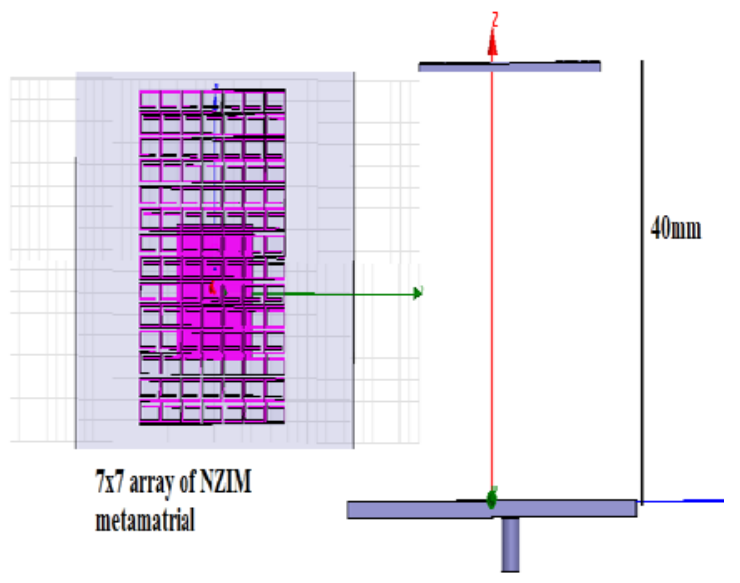

Figure 8: The Schematic Diagram of Proposed Antenna with NZIM Lens: (a) Top View (b) Side View

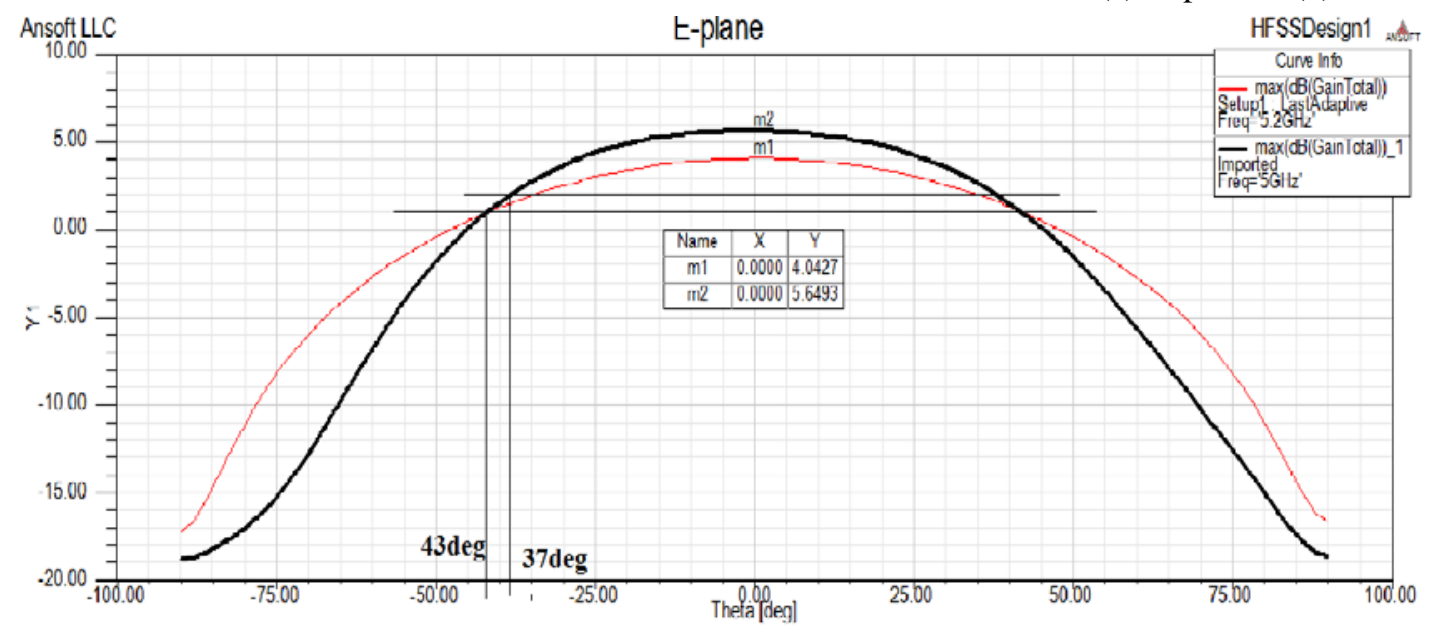

Figure 9: Simulated Radiation Pattern of Basic Patch Antenna Loaded with Single Layer- E-Plane

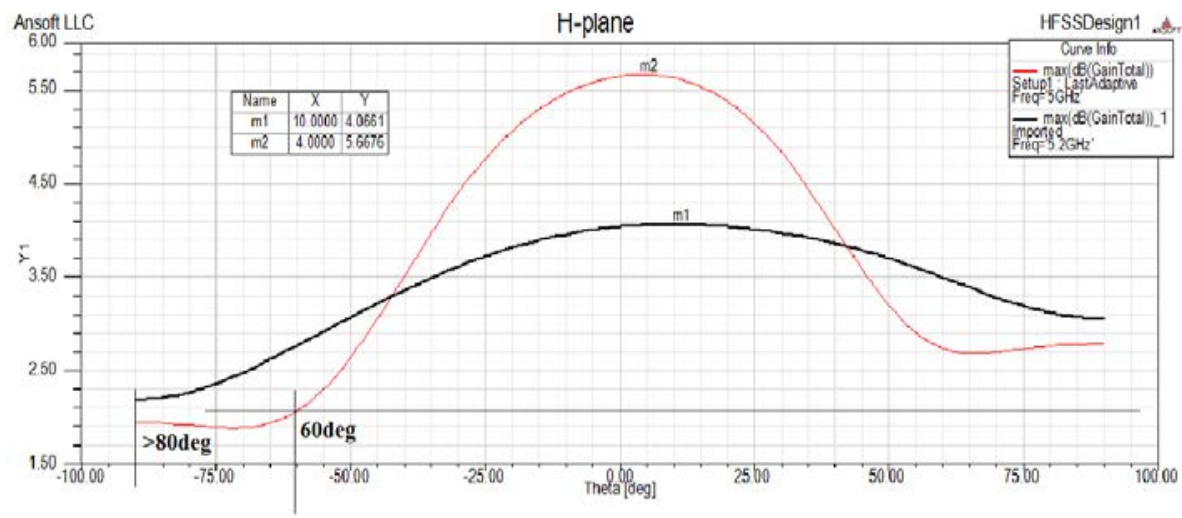

Figure 10: Simulated Radiation Pattern of Basic Patch Antenna Loaded with Single Layer- H-Plane 

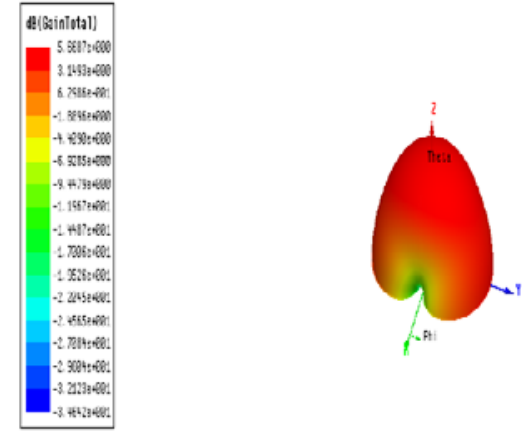

Figure 11: 3D Polar Plot of Gain of Basic Patch Antenna with NZIM Lens

\section{CONCLUSION AND FUTURE ENHANCEMENT}

In this paper, a NZIM unit cell has been proposed. An array of 7 X7 of these NZIM unit cells is used as superstrate structure over the Microstrip Patch Antenna for gain enhancement for WLAN application. The simulated results confirm that the incorporation of NZIM unit cells as superstrate significantly enhances the gain of patch antenna. This structure reduces the HPBW in both E-plane and Hplane and it can further be extended for antenna array system.

\section{REFERENCES}

[1] C. Caloz and T. Itoh, "Electromagnetic metamaterial: transmission line theory and microwave application”, John wiley\&Sons, 2005.

[2] D.R. Smith. W.J. Padilla. D.C. Vier, S.C. Nemat-Nasser and S. Schultz, "Composite medium sith simultaneously negative permeability and permittivity”, Physical Review Letter, Vol.84, No.18, Pp.4184-4187, 2000.

[3] Y. Dong and T. Itoh, "Metamaterial-based antennas", Proceedings of the IEEE, Vol.100, No.7, Pp.2271-2285, 2012.

[4] J. Zhu, M. A. Antoniades, and G. V. Eleftheriades, “ A Compact Triband Monopole Antenna with Single- cell Metamaterial Loading”, IEEE Transactions on Antennas and Propagation, Vol.58, No.4, Pp.1031-1038, 2010.

[5] M. A. Antoniades and G.V. Eleftheriades, “ Multiband Compact Printed Dipole Antenna Using NRI-TL metamaterial loading”, IEEE Transactions on Antennas and Propagation, Vol.60, No.12, 2012.

[6] K. Saurav, D. Sarkar and K.V. Srivastava, "CRLH Unit-cell Loaded Multi-Band Printed Dipole Antenna”, IEEE Antennas and Wireless Propagation Letter, Vol.13, Pp.852-855, 2014.

[7] K. Saurav, D. Sarkar and K.V. Srivastava, "Dual Polarized Dual Band Patch Antenna Loaded with Modified Mushroom Unit cell”, IEEE Antennas and Wireless Propagation Letter, Vol.13, Pp.1357-1360, 2014.

[8] K. Saurav, D. Sarkar and K.V. Srivastava, “ Muti Band Microstrip fed Slot Antenna Loaded With a Spilt Ring Resonator (SRR),” Electronics Letter, Vol.50, No.21, Pp.1498- 1500, 2014.

[9] S.V Reddy, D. Sarkar, K. Saurav and K.V. Srivastava, "A Compact CRLH Unit-cell Loaded Triple-Band Monopole Antenna”, Microwave and Optical Technology Letter, Vol. 57, No.1, Pp. 115-119, 2015.

[10] A. Singh, D. Sarkar, K. Saurav, S.V Reddy and K.V. Srivastava, “A Via-Lens Planar Quad-Band Monopole Antenna Employing Complementary Split Ring Resonator and Interdigital Capacitor”, Processeding of 8th Europpean Conference on Antennas and Propagation, Pp.1193- 1196-855, 2014.

[11] D. Sarkar, K.V. Srivastava and K. Saurav, "A Compact Microstrip- fed Triple Band- Notched Ultra-wideband Monopole Antenna”, IEEE Antennas and Wireless Propagation Letter, Vol.13, Pp.396-399, 2014.
[12] B.I. Wu, W. Wang, J. Pacheco, X. Chen, T. Grzegorezyk and J.A. Kong, "A study of using Metamaterials as antenna substrate to enhance gain", Peogress in Electromagnetics Research, Vol.51, Pp. 295-328, 2005.

[13] S. Enoch, G. Tayeb, P. Sabouroux, N. Guerin and P. Vincent, "A Metamaterial for Directive Emission”, Physical Review Letter, Vol.89, No.21, 2002.

[14] J.P. Turpin, Q. Wu. D.H. Werner, B. Martin, M. Bray, and E. Lier, "Near Zero Index metamaterial Lens Combined With AMC Metasurface for High-Directivity low-Profile Antennas", IEEE Transactions on Antennas and Propagation, Vol.62, No.4, Pp. 192-193, 2014.

[15] Z.H. Jiang and D.H. Werner, "Anisotropic metamaterial lens with a monopole feed for high-gain multi-beam radiation”, Proceedings of IEEE Antennas and Propagation Symposium (APSURSI), Pp. 1346-1349, 2011,

[16] C.A. Balanis, “Antenna Theory: Analysis and Design”, Second Edition, John Wiley and sons, 2016.

[17] X. Chen, T.M. Grzegorczyk, B.I. Wu, J. Pacheco and J.A. Kong, "Robust Method to Retrieve the Constitutive effective parameters of metamaterial”, Physical review E, Vol.70, No.1, 2004,.

[18] H. Chen, L. Ran, J. Huangfu, X. Zhang, K. Chen, T.M. Grzegorczyk and J.A. Kong, "Left-handed materials composed of only S-shaped resonators", Physical Review E, Vol.70, No.5, 2004.

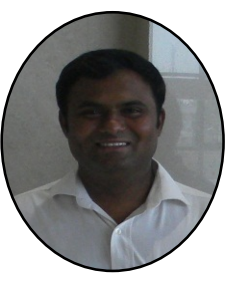

A.S. Pradeep received the BE degree in Electronics and Communication Engineering from UBDT Engineering College, Davanagere, Karnataka and M.tech degree in Electronics from Sir MVIT, Bangalore, Karnataka in 2003 and 2006 respectively. Currently he is persuingPh.D degree from Visvesvaraya Technological University, Belagavi, Karnataka under the guidance of Dr. G. A. Bidkar.He worked as an Assistant Professor in the Department of ECE at RVCE, Bangalore during 20072010. Currently he is working as an Assistant Professor in the Department of ECE at GEC, Hoovinahadagali, since 2010. His research interest include microwave and antenna design.

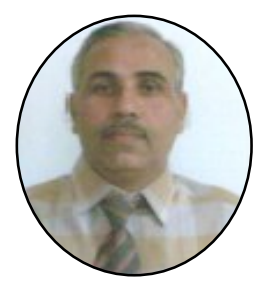

Dr.G.A. Bidkar received the BE degree in Electronics and Communication Engineering from P.D.A. College of Engineering, Gulbarga in 1986, M.E degree in Power Electronics from P.D.A. College of Engineering, Gulbarga University, Gulbarga in 2000 and Ph.D degree in Microwave Electronics from Gulbarga University, Gulbarga in 2013. Currently he is a Professor in Department of E\&C at SDM College of Engineering \& Technology, Dharwad since 2013.His research interests include Smart Antennas, Microwaves, Wireless Communication, MIMO. He is a member of Indian Society for Technical Education (ISTE) and The Institution of Electronics \& Communication Engineer. 